\title{
GENERALIZAÇÃO CARTOGRÁFICA DAS CARTAS DO MAPEAMENTO URBANO NAS ESCALAS 1:2.000, 1:5.000 E $1: 10.000$
}

Cartographic generalization for urban mapping at 1: 2,000, 1:5,000 and 1:10,000

\author{
TATIANA AYAKO TAURA ${ }^{1}$ \\ CLAUDIA ROBBI SLUTER ${ }^{2}$ \\ HENRIQUE FIRKOWSKI ${ }^{2}$ \\ ${ }^{1}$ Embrapa Semiárido \\ BR 428, km 152 - Petrolina-PE \\ Caixa Postal 23 - CEP: 56302-970 \\ ${ }^{2}$ Universidade Federal do Paraná - UFPR \\ Curso de Pós Graduação em Ciências Geodésicas - CPGCG \\ Jardim das Américas - C. Politécnico - Curitiba-PR \\ Caixa Postal 19001 - CEP 81.531-990 \\ tatiana.taura@cpatsa.embrapa.br; \{robbi, firk\}@ufpr.br
}

\begin{abstract}
RESUMO
Na construção de mapas, procura-se representar as feições de maneira que não se percam as suas características geométricas e espera-se que o usuário do mapa compreenda o seu significado independentemente da escala estabelecida para a representação visual. Devido à restrição de espaço para a representação, deve haver a preocupação em simbolizar as informações de forma visível e legível. Se, ao resultado do processo de generalização cartográfica, for aplicada uma simbologia inadequada, pode haver implicações no processo de comunicação cartográfica. Neste trabalho, teve-se por objetivo realizar experimentos de generalização cartográfica para a derivação de representação das feições de vias de acesso, quadras, lotes, edificações e toponímias, nas escalas 1:5.000 e 1:10.000, a partir da escala 1:2.000. O desenvolvimento do trabalho constou da avaliação cartométrica para detectar possíveis problemas geométricos resultantes da redução de escala e a definição dos operadores a serem aplicados às feições. A adoção da simbologia para as escalas menores foi baseada nas respostas obtidas de experimento orientado especificamente à avaliação e escolha da simbologia. A aplicação da simbologia às
\end{abstract}


feições componentes das cartas em escala menor comprovou e reforçou a necessidade de se realizar adequação de símbolos para produtos derivados em escala menor por generalização cartográfica e, portanto, conduziu a resultados coerentes com o conceito de projeto cartográfico.

Palavras-chave: Generalização Cartográfica; Mapas Urbanos; Percepção Visual.

\section{ABSTRACT}

In map production, it is expected that represented features maintain their geometric characteristics in relation to its originals, and it is also expected that the user is able to understand their conveying meaning independently of the visualization scale. Due to space constraints, information represented must be clearly and legibly symbolized. If poor or inadequate symbols are applied to the output features of generalization process, this may result in some undesirable effect on cartographic communication. This work aimed at carrying out experiments on cartographic generalization applied to roads, blocks, parcels, buildings and toponyms for representing at 1:5,000 and 1:10,000 scales, from 1:2,000 maps. The workflow included cartometric evaluation to detect possible geometric problems resultant of scale reduction and further definition of generalization operators. Adopted symbols used for derived maps were defined by means of a practical symbol evaluation experiment. The use of these symbols on generalization derived features proved and reinforced the need for adapting symbols for lower-scale derived products by cartographic generalization, and therefore conducted to results consistent with the concept of cartographic project.

Keywords: Cartographic Generalization; Urban Maps; Visual Perception.

\section{INTRODUÇÃO}

De acordo com os princípios da cartografia, busca-se representar as feições de forma que não se percaa suas características e, ao mesmo tempo, espera-se que o usuário da carta possa compreender o significado dos elementos representados na escala definida. Os símbolos utilizados para representar as feições numa carta são especificados de forma que as feições importantes sejam legíveis e não somente visíveis, e a diferença em forma das feições seja claramente distinguível (BOS, 1984 e KEATES, 1973). Para atender a essas premissas, a representação dessas feições deve ocorrer com um tamanho mínimo, de tal modo que seja perceptível para um usuário.

A qualidade do produto cartográfico, nas escalas derivadas, pode ser afetada por problemas decorrentes da inadequação da simbologia utilizada para representar feições. Um efeito disso é a possibilidade de perda no processo de comunicação cartográfica. A derivação de cartas em escala menor do que aquela para a qual os dados foram coletados pode acarretar problemas de ordem geométrica e/ou de ordem semântica. Pelo fato da escala de representação condicionar o montante de 
informação a representar numa carta, a realização da generalização cartográfica torna-se indispensável. O conjunto de ações que se realiza para manter o poder informativo de uma representação é composto pelas operações de seleção, eliminação e combinação, dentre outras. Estas operações são realizadas com vistas à manutenção da comunicação cartográfica que está intimamente ligada à legibilidade e ao conteúdo semântico representado. Neste trabalho o objetivo foi propor a representação das feições de vias de acesso, quadras, lotes, edificações e toponímias, cuja definição de simbolização depende da utilização dos operadores de generalização cartográfica e dos resultados obtidos em testes de percepção visual para avaliar os tamanhos mínimos de símbolos. Os testes foram realizados a partir de uma avaliação da percepção de símbolos cartográficos adotados na padronização das feições e as categorias de informações especificadas nas escalas 1:2.000, 1:5.000 e 1:10.000 definidas pela Câmara Técnica de Cartografia e Geoprocessamento do Estado do Paraná - CTCG. As operações de generalização cartográfica propriamente dita foram executadas no ambiente do programa Maxicad SA versão 32, pelo fato dos dados utilizados nos experimentos serem nativos deste programa.

\section{GENERALIZAÇÃO CARTOGRÁFICA}

Um usuário que observa uma carta procura entender o que está nela representado e passa conscientemente e inconscientemente a estabelecer relações de diversas naturezas tanto entre aquilo que vê quanto entre aquilo que já se constitui em conhecimento seu. Como as cartas são consideradas também como meios de comunicação, a informação representada pelos símbolos cartográficos deve proporcionar ganho de conhecimento que decorre do processo de comunicação cartográfica (ROBBI, 2000). A importância do uso de um modelo de comunicação para cartas está no fato de que o cartógrafo deve ser capaz de entender os requisitos do usuário da carta e representar as informações de forma apropriada, uma vez que a carta é o canal de comunicação com o usuário. Para garantir essa comunicação, todos os símbolos devem ser identificados sem esforço ou ambigüidade, onde quer que ocorram (KEATES, 1989), ou seja, os símbolos devem ser perceptíveis e distinguíveis pelo usuário.

De acordo com BOS (1984), percepção visual é uma composição entre a detecção de um objeto no campo visual e habilidade de compreender seu significado. Outra habilidade envolvida na legibilidade dos símbolos é a acuidade visual, que é definida como a habilidade dos olhos em detectar pequenos objetos ou detalhes espaciais e a capacidade de discriminá-los. Ou seja, a acuidade visual pode ser expressa como a deteç̧ão e discriminação do tamanho mínimo de um objeto ou marca gráfica a certa distância de leitura sob certas condições de contraste.

O problema cartográfico relativo à quantidade de informação disponível e ao espaço existente para sua representação ocorre nos casos de redução de escala de representação. Uma das possíveis consequências da redução da escala é a 
necessidade de realizar a generalização cartográfica. Quanto menor for a escala de um mapa, maior será o grau de generalização a que os objetos ali representados foram submetidos.

A generalização cartográfica deve ser realizada como forma de preservar a comunicação cartográfica em representações produzidas por derivação de cartas já existentes. A generalização cartográfica consiste de um conjunto de operações responsáveis pelo restabelecimento das condições de comunicação que os dados cartográficos perderam pelo fato de haver redução de escala (KEATES, 1989).

A generalização, de acordo com McMASTER \& SHEA (1992), é um modelo em que são reconhecidos e explicitados os requisitos teóricos que justificam a realização do processo de generalização. Os requisitos devem manter eficiente o processo de comunicação cartográfica apesar da imposição de redução de escala de representação e devem, satisfazer as necessidades do usuário, e os requisitos computacionais. Dentre os elementos que permeiam esse processo, encontra-se a avaliação cartométrica.

Avaliação cartométrica consiste nos procedimentos voltados à identificação das condições geométricas existentes após a realização de uma redução de escala, que possam demandar a aplicação de operadores de generalização cartográfica. Estas condições são:

- $\quad$ Congestionamento - superlotação de símbolos pela alta densidade de feições, e que pode prejudicar o aspecto de comunicação de uma carta;

- Coalescência - aproximação excessiva ou sobreposição de entre as feições;

- $\quad$ Conflito - como a incompatibilidade entre a feição representada e aquilo que lhe serve de fundo;

- Complicação ou Dificuldade - técnicas não convencionais aplicadas para a representação de feições. Deve-se levar em conta diversos fatores, como complexidade dos dados, seleção das técnicas de interação, de níveis de tolerância

- Inconsistência - consequência da aplicação não uniforme das decisões que implicam em distintas operações de generalização em uma região mapeada; e

- Imperceptibilidade - ocorrência ou existência de feições cuja dimensão em escala é menor do que o tamanho mínimo representável no mapa.

As transformações espaciais são realizadas por operadores que tratam os dados geométricos, e produzem alterações nos dados digitais do ponto de vista geográfico e/ou topológico; e em seus atributos, pela manipulação das características secundárias dos elementos. Há situações em que estes operadores são tratados de forma isolada e há situações em que devem necessariamente ser tratados de forma dependente (McMASTER \& SHEA, 1992). Na Figura 1, apresentam-se os operadores geométricos utilizados nesse trabalho. 
Figura 1 - Operadores de transformação espacial.

\begin{tabular}{|c|c|c|}
\hline Operadores & Carta original & \\
\hline Seleção/Eliminação & & \\
\hline Colapso & & \\
\hline Agregação & \\
\hline Exagero & \\
\hline Deslocamento & \\
\hline Realce & \\
\hline
\end{tabular}

FONTE: adaptado de McMASTER \& SHEA (1992)

\section{METODOLOGIA}

A metodologia consiste em:

1. Realizar a redução da escala de visualização/impressão de 1:2.000 para 1:5.000 e 1:10.000;

2. Realizar a avaliação visual destas imagens em busca da ocorrência de situações que demandem a aplicação de generalização;

3. Determinar que operações de generalização devem ser realizadas;

4. Realizar as operações de generalização; e

5. Aplicar a simbologia aos dados generalizados. 
Iniciou-se a generalização cartográfica das classes de feições: vias urbanas; quadras e lotes; edificações e toponímias com a avaliação cartométrica. As cartas na escala 1:2.000 sofreram redução de escala para as escalas 1:5.000 e 1:10.000, sem que houvesse modificação na representação das feições. Estas cartas (1:5.000 e 1:10.000) foram impressas e então foram identificadas as situações em que ocorre o congestionamento, a coalescência, o conflito, a complicação, a imperceptibilidade e a inconsistência para cada classe de feição analisada. Esta avaliação foi realizada com base no modelo conceitual de McMASTER \& SHEA (1992), conforme a Figura 2.

Após a detecção dos problemas, definiram-se os operadores aplicados para cada classe de feição de forma a solucionar os problemas encontrados consequentes da redução de escala. Aplicaram-se os operadores de generalização cartográfica para cada classe de feição nas cartas na escala 1:2.000 e o resultado foi impresso na escala 1:5.000. Há casos em que as feições sofreram somente redução de tamanho, pois não foram alterados a dimensão espacial, a definição conceitual e os atributos. Houve feições que sofreram mudanças de atributo e de escala de medida e passaram por um processo de mudança de simbologia, com alterações no estilo dos traços, espessuras das linhas, tamanhos da fonte dos textos e cores.

Figura 2 - Condições que demandam a generalização cartográfica.

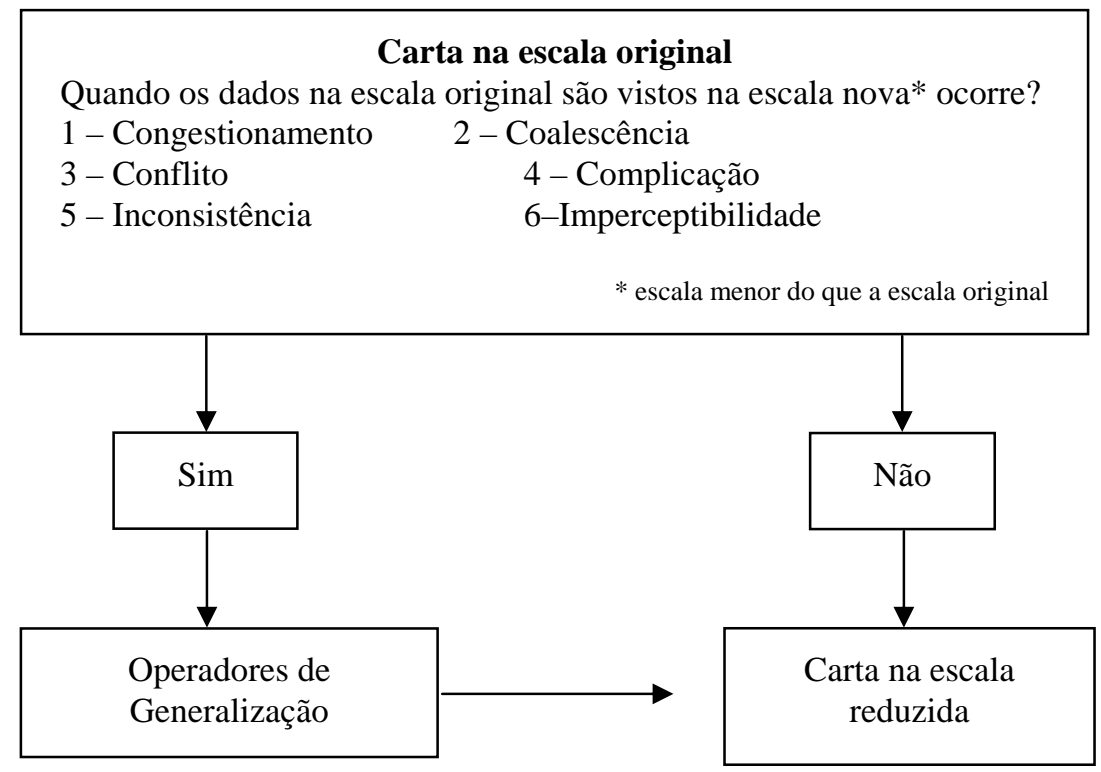

FONTE: adaptado de FIRKOWSKI (2002). 
Para a generalização para a escala 1:10.000, partiu-se do resultado da generalização da etapa anterior, escala 1:5.000, e foram aplicados os mesmos operadores, ou seja, a carta na escala 1:5.000 foi reduzida em escala e seu resultado impresso na escala 1:10.000 para que se procedesse a avaliação sobre as consequências da redução de escala, tal como na generalização da escala 1:2.000 para a escala 1:5.000.

Para não haver perda no montante de informação transmitida no produto generalizado, realizou-se um teste para avaliar o tamanho mínimo com que o símbolo é perceptível e distinguível ao usuário. No processo de generalização cartográfica, as mudanças na simbologia respeitaram os tamanhos mínimos avaliados no teste para que se preservasse a legibilidade e a visibilidade.

\subsection{Teste de percepção visual}

O experimento consistiu em:

1. Definir um conjunto de símbolos para algumas feições;

2. Produzir imagens com esta simbologia;

3. Estabelecer o conjunto de questões e possibilidades de respostas;

4. Aplicar os testes e tabular os resultados; e

5. Analisar as respostas dos entrevistados.

Foram selecionadas feições cuja simbologia estabelecida consistia de símbolos pontuais, símbolos lineares e símbolos de área. Além da simbologia, foram verificadas diferentes fontes e alturas de textos para toponímias utilizadas nas cartas topográficas.

Usou-se a publicação Cartographic Generalization da Sociedade Suíça de Cartografia (Swiss Society of Cartography, 1977) como referência para a especificação do experimento. Segundo a publicação, a redução dos símbolos deve ser feita até a condição em que é possível discriminá-los. A publicação apresenta uma lista de símbolos em preto e branco com a definição dos tamanhos mínimos. Além destes símbolos propostos na publicação, foram incluídos outros símbolos pontuais, lineares e de área comuns em cartas topográficas. Foram realizados 10 experimentos para que se pudesse analisar a percepção visual de símbolos com usuários. Para cada experimento foram oferecidas 7 opções de tamanhos de símbolos. O teste foi aplicado a 73 entrevistados e em cada questão o entrevistado deveria responder acerca dos símbolos, a partir de que tamanho de símbolo se sentiu capaz de discriminá-los.

\section{RESULTADOS}

O tempo necessário aos entrevistados para realizar o teste foi de 5 minutos e a média de idade dos entrevistados foi de 24 anos. O entrevistado foi solicitado a informar se era portador de algum problema de visão, e se no momento do teste usava óculos ou lentes de contato. 
Na Figura 3, apresenta-se um subconjunto dos símbolos propostos na publicação da Sociedade Suíça de Cartografia (Swiss Society of Cartography, 1977) e os símbolos incluídos nos experimentos da percepção visual. Na segunda coluna apresentam-se os resultados do teste de percepção visual e na terceira coluna cita-se os tamanhos mínimos segundo a publicação da Sociedade Suíça de Cartografia.

Figura 3 - Conjunto dos símbolos que sofreram avaliação de discriminação com os valores dimensão mínima assinalados pelos entrevistados e os valores correspondentes na publicação da Sociedade Suíça de Cartografia. Nota: (-) não há informação na Swiss Society of Cartography (1977).

\begin{tabular}{|c|c|c|}
\hline Símbolo & Dimensão proposta (mm) & $\begin{array}{c}\text { Swiss Society of } \\
\text { Cartography (mm) }\end{array}$ \\
\hline 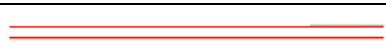 & 0,20 & 0,25 \\
\hline 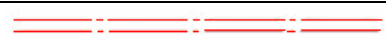 & 0,25 & - \\
\hline 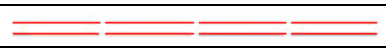 & 0,20 & - \\
\hline$\overline{\overline{\bar{\nu}}} \overline{\overline{\bar{\nu}}}$ & 0,25 & - \\
\hline$==ニ=ニ====$ & 0,25 & - \\
\hline & 0,30 & - \\
\hline Espacamento & 0,25 & 0,25 \\
\hline Espaçamento & 0,25 & - \\
\hline $\begin{array}{l}\text { AV MANOEL RIBAS } \\
\text { (Altura das letras do tipo } \\
\text { arial) }\end{array}$ & 1 & 1,20 \\
\hline $\begin{array}{c}\text { RUA MARECHAL } \\
\text { DEODORO (Altura das } \\
\text { letras do tipo Times new } \\
\text { Roman) }\end{array}$ & 1,0 & 1,20 \\
\hline (Diâmetro) & 0,50 & - \\
\hline (Diâmetro) & 0,50 & 0,30 \\
\hline$\Delta($ Lado $)$ & 0,80 & \\
\hline$\triangle$ (Lado) & 0,80 & 1,00 \\
\hline (Lado) & 0,30 & 0,30 \\
\hline$\square$ (Lado) & 0,50 & - \\
\hline$\square$ (Lado vermelha) & 0,50 & - \\
\hline
\end{tabular}


Com base nos resultados do teste para avaliação da percepção visual do espaçamento entre linhas paralelas de diferentes traços, pode-se afirmar que este é diferente para cada tipo de traço e a percepção de linhas paralelas ocorreu com a distância de $0,20 \mathrm{~mm}$ enquanto que para os outros tipos de traços é de $0,25 \mathrm{~mm}$. Segundo Swiss Society of Cartography (1977), a percepção de linhas paralelas contínuas ocorre quando estas linhas estão afastadas entre si de $0,25 \mathrm{~mm}$. Para o experimento de espaçamento entre feições de área e linha, o resultado concordou com esta publicação, na medida para ambos os símbolos de $0,25 \mathrm{~mm}$. O experimento seguinte consistiu em conhecer o tamanho mínimo de lado em um polígono que o usuário é capaz de perceber em uma feição de área e constatou-se que o menor tamanho detectado, para os testes realizados, é de $0,3 \mathrm{~mm}$.

Para altura mínima de textos foram testados 2 tipos de fontes: arial e times new roman. Constatou-se, pelas respostas dos entrevistados, que a altura mínima do texto que admitiu leitura, para as duas fontes foi de 1,0mm. Para Swiss Society of Cartography (1977), a altura mínima de texto deve ser de 1,2mm.

Os resultados dos testes de discriminação de símbolos geométricos são apresentados na Tabela 1 . A Tabela 1 contém valores de discriminação entre círculos preenchidos e vazados. Constatou-se que o resultado do experimento do círculo sólido foi mais disperso, isto é, os entrevistados escolheram várias opções enquanto no experimento do círculo vazado se concentraram em somente três opções. Isso se deve ao fato de que o círculo sólido pode ser confundido com um ponto, o que levou alguns entrevistados a procurar por um círculo sólido, e outros a entender que o ponto seria suficiente para caracterizar o símbolo pontual. Consequentemente, no experimento de círculo sólido, 50,7\% dos entrevistados foram capazes de ver o símbolo com diâmetro inferior a $0,5 \mathrm{~mm}$. Em relação ao círculo vazado, 68,2\% somente perceberam o símbolo a partir de $0,5 \mathrm{~mm}$. Segundo Swiss Society of Cartography (1977) o diâmetro mínimo de um círculo vazado é de $0,3 \mathrm{~mm}$.

Tabela 1 - Resultado da percepção do diâmetro mínimo do círculo.

\begin{tabular}{c|c|c}
\hline \multicolumn{3}{|c|}{ Córculo Sólido } \\
\hline Medida (mm) & 12 & Total (\%) \\
\hline 0,05 & 2 & 17,4 \\
\hline 0,08 & 2 & 2,9 \\
\hline 0,10 & 2 & 2,9 \\
\hline 0,15 & 5 & 2,9 \\
\hline 0,20 & 12 & 7,2 \\
\hline 0,30 & 25 & 17,4 \\
\hline 0,50 & 9 & 36,3 \\
\hline 0,80 & Círculo Vazado \\
\hline \multicolumn{3}{c}{}
\end{tabular}




\begin{tabular}{c|c|c}
\hline 0,05 & - & - \\
\hline 0,08 & - & - \\
\hline 0,10 & - & - \\
\hline 0,15 & - & - \\
\hline 0,20 & - & - \\
\hline 0,30 & 15 & 21,7 \\
\hline 0,50 & 47 & 68,2 \\
\hline 0,80 & 7 & 10,1 \\
\hline
\end{tabular}

Os testes de discriminação dos triângulos sólidos e vazados apontaram para um tamanho mínimo de lado de 0,8mm, medida menor que a apresentada em Swiss Society of Cartography (1977), que apresenta para o triângulo vazado o comprimento mínimo de lado de $1,0 \mathrm{~mm}$. Nos testes de discriminação do menor tamanho do quadrado sólido identificado foi o mesmo definido em Swiss Society of Cartography (1977), cujo valor sugerido é de $0,3 \mathrm{~mm}$, apontado por cerca de $46 \%$ dos entrevistados. Para os quadrados vazados o tamanho foi de $0,5 \mathrm{~mm}$ de comprimento de lado, independentemente da cor usada.

\subsection{Generalização Cartográfica das Feições Urbanas}

\subsubsection{Generalização das Vias Urbanas}

Foram trabalhadas, nessa etapa, as classes das feições de vias, pontes e viadutos, túneis e trincheiras, canteiros, rotatórias e cruzamentos. Nas especificações de categorias das feições cartográficas estabelecidas pela Comissão Técnica de Cartografia e Geoprocessamento (CTCG, 1996) e utilizadas pelo Paranacidade, as vias são classificadas e simbolizadas conforme se apresenta na Figura 4.

Figura 4 - Representação de diferentes classes de vias.

\begin{tabular}{|c|c|}
\hline Simbologia & Classes de Vias urbanas \\
\hline$\overline{\overline{ }} \overline{=} \overline{=}$ & Via pavimentada com meio fio \\
\hline & Via pavimentada sem meio fio \\
\hline$\overline{\bar{z}}=-$ & Via não pavimentada com meio fio \\
\hline$\overline{\overline{ }} \overline{\overline{ }} \overline{\overline{ }} \overline{\overline{2}}$ & Via não pavimentada sem meio fio \\
\hline$\equiv \equiv \equiv \equiv=\equiv \equiv \equiv \equiv \equiv \equiv$ & Via em construção \\
\hline
\end{tabular}


Segundo ROBINSON \& LEE (1994), a generalização das vias urbanas tem efeito sobre outras feições no mapa, de modo que deve ter prioridade sobre as outras feições na carta. Seguindo esta recomendação, a primeira classe de feição a sofrer operadores de generalização foi a classe de feições composta pelas vias de acesso.

Segundo os resultados do teste de percepção, o espaçamento de linhas paralelas é perceptível aos entrevistados a partir de 0,20mm. Nas escalas trabalhadas, os espaçamentos entre as vias são percebidos mesmo após as reduções de escala, pois têm dimensão maior do que mínimo identificável. Deve-se considerar, na generalização, que as vias acompanham outras informações como os canteiros centrais e nomes das ruas, e devem ter um espaçamento suficiente para representar essas informações de forma a não dificultar percepção, isto é, deve haver um ajuste no espaçamento entre os traços após a mudança de escala. Para a representação apropriada dessas informações, as vias devem receber o tratamento da generalização e propõe-se que sejam aplicadas as operações de exagero e deslocamento. As pontes, viadutos, trincheiras e túneis são feições importantes do sistema viário. Estas feições são representadas de forma legível na escala original, porém, nas reduções para as escalas menores passam a ser afetadas por problemas de legibilidade, coalescência do símbolo do túnel/trincheira com as vias e a imperceptibilidade. Propôs-se para essas feições a aplicação dos operadores de deslocamento e de exagero (1:5.000), e para a generalização na escala 1:10.000, será necessário o realce do símbolo. Na Figura 5 apresenta-se o resultado da generalização para cada escala de forma ampliada.

Figura 5 - Modificação dos símbolos, de acordo com a escala, de pontes/viadutos e túneis/trincheiras.

\begin{tabular}{|c|c|c|c|}
\hline Feição & Símbolo & 1:5.000 (ampliada) & 1:10.000 (ampliada) \\
\hline $\begin{array}{l}\text { Pontes e } \\
\text { viadutos }\end{array}$ & $\frac{111}{>}$ & $\frac{111 / 1}{\longrightarrow}$ & \\
\hline $\begin{array}{l}\text { Túneis e } \\
\text { trincheiras }\end{array}$ & $\stackrel{1}{\prime}$ & $\frac{\perp \quad L}{T}$ & \\
\hline
\end{tabular}

Na avaliação cartométrica dos canteiros foi identificada a coalescência para o caso da redução de escala para 1:10.000, a espessura do canteiro reduziu-se a uma linha. O efeito que isso proporciona na representação é de realce, pois a linha tornase mais espessa e a feição se sobressai na imagem. Essas feições sofrem mudanças em primitiva gráfica (de área para linha) sem perder a característica da forma do 
canteiro. Assim, o operador de colapso foi aplicado, isto é, realiza-se uma mudança de dimensão, passa de representação de área para representação de linha (Figura 6).

Figura 6 - Etapas de generalização dos canteiros.

\begin{tabular}{|c|c|c|}
\hline Original & Colapso & Exagero \\
\hline & & \\
\hline
\end{tabular}

As rotatórias e os cruzamentos são vias que têm detalhes importantes para o tráfego. Nas escalas reduzidas, esses mesmos canteiros se tornam imperceptíveis, e as vias formadoras da rotatória se fundem em uma só, isto é, ocorre coalescência. Essas feições devem ser enfatizadas após a redução de escala, para isso foram aplicados os operadores de seleção/eliminação e de exagero. Desse modo são eliminados pequenos detalhes que são imperceptíveis, e, após isso, aplica-se o operador de exagero, de modo a proporcionar as condições gráficas necessárias para poder discriminar estas feições.

\subsubsection{Generalização das Edificações}

Na tabela da CTCG, de categorias das feições cartográficas para escala 1:2.000, classificam-se feições de edificações em residenciais, comerciais, industriais, administração pública, edificações de cemitérios, escolas, igrejas, hospitais. A realização da avaliação cartométrica apontou a existência de congestionamento de informações, a de imperceptibilidade de símbolos, de coalescência entre feições e de inconsistência.

No processo de seleção foi atribuído um grau de importância a cada elemento, e este serviu como determinante de sua representação ou eliminação na escala destino. Os autores ROBBINSON et al. (1978) e MORRISON (1975), sugerem utilizar como critério de grau de importância. O primeiro critério a ser aplicado é o critério de tamanho, o segundo é de proximidade e o terceiro critério é dado pela combinação de tamanho com proximidade. Primeiramente, foram omitidas as edificações cuja representação teria área menor do que o mínimo identificável, que, de acordo o resultado do teste de percepção visual (quadrado vazado), é um valor de $0,25 \mathrm{~mm}^{2}$. Para a operação de simplificação, eliminaram-se pontos que formam lados inferiores a $0,30 \mathrm{~mm}$, conforme o teste determinou para o tamanho mínimo de lado perceptível.

Para a operação de agregação, existem diversas maneiras para tratar feições próximas. Normalmente os objetos pequenos (definidos como menos importantes) 
são deslocados aos objetos grandes (objetos mais importantes). A fim de se estabelecer uma direção para a união das feições, utilizaram-se os pontos finais das faces da edificação (pontos definidores) e esta direção de união pode ser associada à altura do triângulo (h) ou a menor distância de uma das faces internas do triângulo (d) (Figura 7). No experimento, agregaram-se edificações de mesma classe com distância entre as feições menores $0,25 \mathrm{~mm}$ da escala.

Figura 7 - Etapas para agregação de edificações

Direçäo da operaçäo em relaçäo a altura (h)
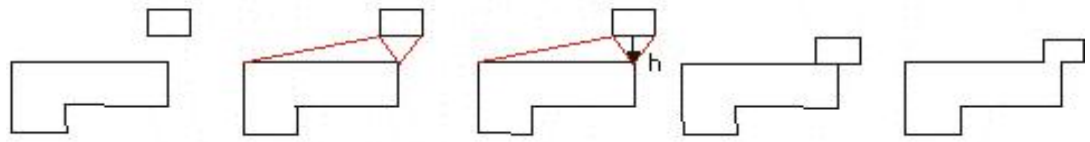

Direçẫo da operaçẫo em relaçẫo a menor distância (d)
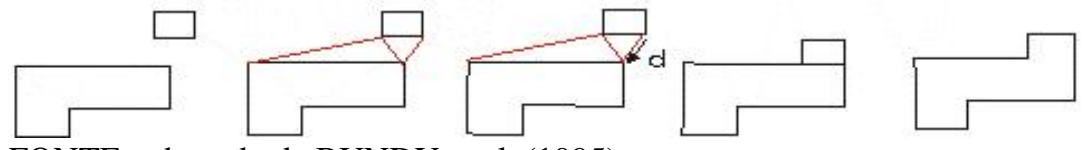

FONTE: adaptado de BUNDY et al. (1995)

Para evitar a coalescência entre as outras feições com as vias, é necessário realizar o deslocamento das edificações. Caso haja edificações de grande importância, deve-se aplicar o operador de exagero para que estas possam ser enfatizadas na carta. Há casos em cartas, em que algumas edificações encontram-se distantes do aglomerado urbano e não ocorre o congestionamento ao se reduzir a escala. Por isso tais edificações foram denominadas nesse trabalho de construções isoladas. A sua existência isolada implica na necessidade de sua permanência, e com isso não se pode aplicar a mesma regra de generalização baseada em dimensão, que se usa em áreas urbanas. Esse problema chama-se de inconsistência. Essas feições receberam atenção na fase da seleção para que não fossem eliminadas. Essa situação pode ser vista na Figura 8, em que apresentam-se dois fragmentos de uma mesma carta na escala aproximada 1:3.500. Na Figura 8.a apresentam-se pequenas construções isoladas, enquanto na Figura 8.b apresenta-se um aglomerado de edificações.

As reduções de escalas para 1:10.000 resultaram em muitas edificações imperceptíveis. Se essas representações de edificações são cemitérios, escolas, igrejas e hospitais não devem ocorrer omissão pois são feições importantes em uma carta. Essas informações geralmente são acompanhadas por um símbolo pictórico. 
Observaram-se casos em que essas feições se encontram próximas entre si, isto é, coalescentes como pode ser visto na Figura 9. Nesta figura mostram-se duas escolas e uma igreja que estão muito próximas. Para a generalização dessas feições, além dos operadores aplicados às edificações, também foi realizado o deslocamento das toponímias para que ocupassem uma posição adequada em relação às demais feições, e foi realizada a adequação do tamanho do símbolo pictórico na redução de escala. Para o caso da proximidade dessas informações, como exemplo escola e igreja, sugere-se que as feições sejam deslocadas para evitar que as edificações se sobreponham como representado na Figura 9.

Figura 8 - Comparação entre construções isoladas e edificações num aglomerado urbano.

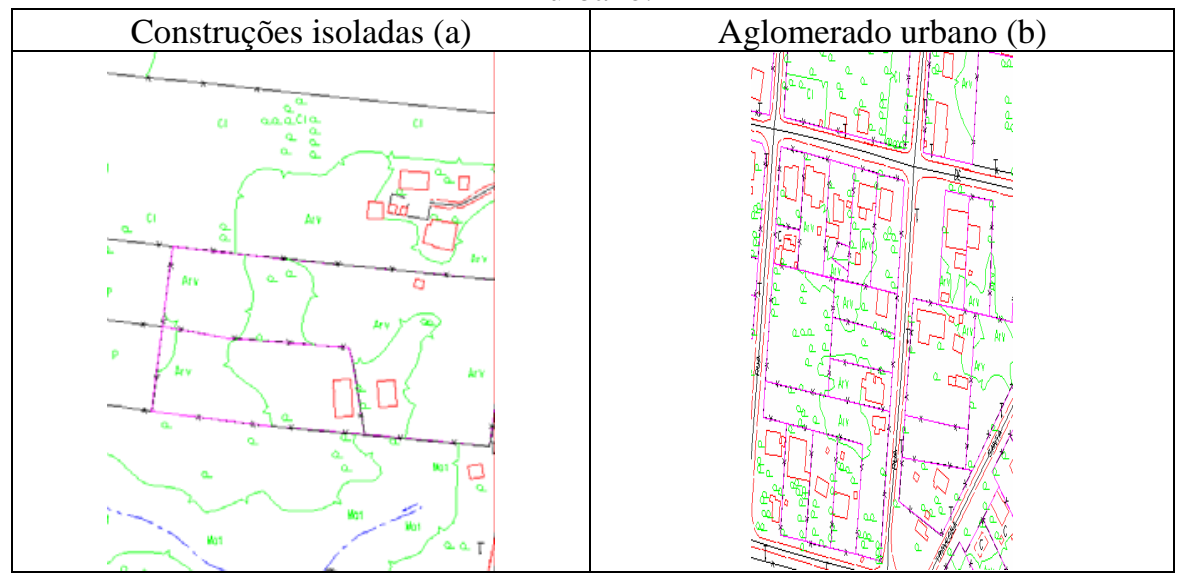

Figura 9 - Operação de deslocamento de edificações.
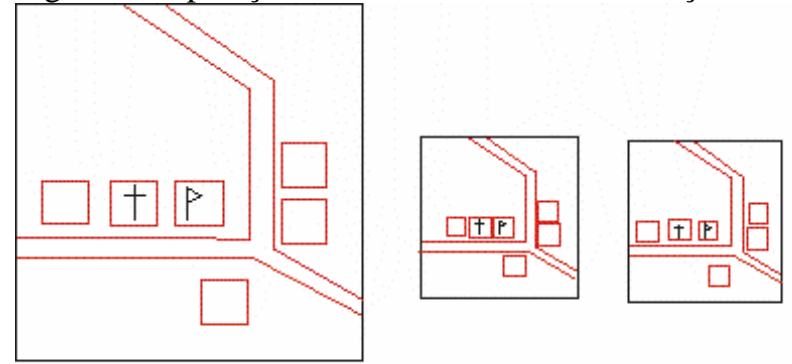

\subsubsection{Generalização das Quadras e Lotes}

As quadras, na escala origem de 1:2.000, são polígonos cujo interiores contêm informações de lotes e outros elementos da superfície como as edificações, as 
árvores, os postes, as áreas verdes. Como consequência da redução de escala os limites das quadras e dos lotes sofrem coalescência. Nas quadras, há informações de alinhamento predial, que geralmente acompanham a fachada dos lotes. Com a realização da redução de escala, para a escala 1:5.000, observa-se que o espaçamento entre a quadra e o alinhamento é perceptível, porém após a redução para a escala 1:10.000 ocorre coalescência. Para solucionar o problema aplicou-se a generalização sobre essas feições com a eliminação das feições de alinhamento predial. Para a representação não se tornar complexa na escala 1:10.000, os lotes também foram omitidos para evitar o problema de congestionamento. Na Figura 10 exemplifica-se, de forma ampliada, uma quadra na escala 1:2.000 e seu resultado na escala generalizada 1:10.000.

Figura 10 - Generalização das quadras e lotes.

(ampliada)

\subsubsection{Generalização das Toponímias}

As toponímias são informações presentes nas cartas topográficas, porém elas não existem como objetos na superfície terrestre. As toponímias, por essa razão, podem congestionar a carta, mas são de necessárias e importantes para o reconhecimento das informações representadas. Devido a esse fato, para qualquer redução de escala, são necessárias adaptações em tamanho para que o texto mantenha sua proporção e seja possível a leitura. Na generalização dessas informações ocorre a omissão que acontece em caso de feições que foram 
eliminados durante sua generalização cartográfica. Os topônimos que permaneceram na representação em escala reduzida sofreram apenas uma adaptação no seu tamanho. Segundo o teste de percepção para texto, o tamanho mínimo é de $1,00 \mathrm{~mm}$, e este valor foi definido para a generalização nesse trabalho independentemente da escala.

\section{CONCLUSÃO}

O objetivo principal neste trabalho foi realizar a experimentação de generalização de feições urbanas e aplicar uma simbologia cartográfica, em parte estabelecida por meio de testes de percepção para estar de acordo com a teoria da comunicação cartográfica. O objetivo foi alcançado com os resultados obtidos com a aplicação dos operadores de generalização cartográfica e com a realização do teste de percepção de símbolos, que serviu como referência para a proposição de símbolos apropriados às escalas reduzidas 1:5.000 e 1:10.000. A representação gráfica dessas feições foi realizada de acordo com as etapas de projeto cartográfico, em que os processos de abstração e generalização estão presentes. A realização da avaliação cartométrica evidenciou a subjetividade envolvida no processo de identificação das condições geométricas na definição e na aplicação dos operadores de generalização.

Constata-se, que a subjetividade envolvida no processo de generalização pode conduzir a diferentes resultados para a mesma proposição de derivação de cartas em escalas menores se diferentes cartógrafos realizarem a tarefa. Assim, entendeu-se que, mesmo que haja regras claras para aplicar operadores de generalização, a subjetividade envolvida no processo pode levar a resultados diferentes.

Os testes de percepção mostraram que as sugestões de dimensão de referência propostas em Swiss Society of Cartography (1977), com o acréscimo de outros símbolos se confirmaram em sua maioria. A adoção de tamanhos mínimos, conforme apontado nos testes realizados, contribuiu para a manutenção da comunicação cartográfica dos produtos derivados.

\section{REFERÊNCIAS BIBLIOGRÁFICAS}

BOS, E. S. Cartographic symbol design. Lecture-notes. ITC,1984, 85p.

BUNDY, G. L. et al. Holistic generalization of large-scale cartographic data. In: Müller, J. C.; Lagrange, J.P.; Weibel, R. ed. GIS and Generalization Methodology and Practice, London, Taylor e Francis, 1995. p 106-119.

CTCG - Câmara Técnica de Cartografia e Geoprocessamento . Recomendação Técnica CTCG - 001/96 Padronização das Escalas Utilizadas em Trabalhos Cartográficos. Curitiba, 1996. 
FIRKOWSKI, H. Generalização Cartográfica de Grades Retangulares Regulares Baseada na Teoria Matemática da Comunicação. Tese de Doutorado, 2002. Universidade Federal do Paraná, Curitiba/PR

KEATES, J.S. Cartographic design and production. Harlow, Grã-Bretanha: Longman, 1973. 240p.

KEATES, J.S. Cartographic design and production. 2.ed. New York, Longman Scientific and Technical, 1989. 266p.

McMASTER, R.B.; SHEA, K.S. Generalization in Digital Cartography. 1.ed. Washington: Association of American Geographers, 1992. 133p.

MORRISON, J. L. Map Generalization: Theory, Practice, and Economics, In: Second International Symposium on Computer-Assisted Cartography, 1975.

ROBBI, C. Sistema para visualização de informações cartográficas para planejamento urbano. Tese de doutorado, 2000. INPE, São José dos Campos $\mathrm{SP}$.

ROBINSON, A H., RANDALL S., MORRISON, J. L. Morrison. (1978). Elements of Cartography. 4 ed. New York: John Wiley and Sons, Inc

ROBINSON, G. J.; LEE, F. An automated generalization system for large scale topographic maps. In: WORBOYS, M. F. ed. Innovations in GIS. New York, Taylor \& Francis, 1994.

Swiss Society of Cartography. Cartographic Generalization, Cartographic Publication Series n. 2, 1977. 61p.

(Recebido em novembro de 2009. Aceito em abril de 2010.) 